\title{
The Role of Life Skills Training In Developing Emotional Maturity and Stress Resilience among Adolescents
}

\author{
Shwetha. B. $\mathrm{C}^{1}$
}

\section{ABSTRACT}

Resilience has been defined as "the ability of an individual to function competently in the face of adversity or stress.”(Kirby and Fraser, 1997).

Life Skills are the abilities for adaptive and positive behavior that enable individual to deal effectively with the demands and challenges of everyday life - WHO.

Emotional Maturity is the ability to monitor one's own and other people's emotions, to discriminate between different emotions and label them appropriately, and to use emotional information to guide thinking and behavior.

Life skills training is used to help adolescents not only acquire knowledge, but also to develop relevant skills to enable them to reduce the risk of behaviors and negative consequences (Botvin \& Griffin, 2004).This skills training is one of the best alternative strategies for the proper practice in essential abilities for managing adolescent life, particularly decision-making and critical thinking ability by considering information and behavior consequences, and ability in recognition of strong feelings in one's self and others to modulate one's own behavioral response, resolve disagreements, and follow rules in a productive and healthy manner (WHO,2003).

The present study focuses on the impact of Life Skill Training Program on Emotional Maturity and Stress Resilience among adolescents. To examine the same the sample of 30 adolescents were given the Life Skill Training and 30 adolescents didn't receive any Life Skill Training and both the groups were administered with Emotional Maturity Scale and The Resilience Scale. The research findings indicated that there is a significant difference between the experimental and control group; experimental group which received Life Skill Training had high Emotional Maturity and high stress resilience compared to untrained group.

Keywords: Life Skill, Emotional Maturity, Stress, Resilience, Adolescents.

\footnotetext{
${ }^{1}$ Lecturer, BMS College for Women, Bangalore, Karnataka (C) 2015 I Shwetha, B; licensee IJIP. This is an Open Access Research distributed under the terms of the Creative Commons Attribution License (http://creativecommons.org/licenses/by/2.0), which permits unrestricted use, distribution, and reproduction in any Medium, provided the original work is properly cited.
} 


\section{The Role of Life Skills Training In Developing Emotional Maturity and Stress Resilience among Adolescents}

Life skills are abilities for adaptive and positive behavior that enable individuals to deal effectively with the demands and challenges of everyday life(WHO) .Described in this way, skills that can be said to be life skills are innumerable, and the nature and definition of life skills are likely to differ across cultures and settings. However, analysis of the life skills field suggests that there is a core set of skills that are at the heart of skills-based initiatives for the promotion of the health and well-being of children and adolescents. These are listed below:

- Decision making

- Problem solving

- Creative thinking

- Critical thinking

- Effective communication

- Interpersonal relationship skills

- Self-awareness

- Empathy

- Coping with emotions

- Coping with stress (WHO/MNH/PSF/93.7A.Rev.2)

Decision making helps us to deal constructively with decisions about our lives. This can have consequences for health if young people actively make decisions about their actions in relation to health by assessing the different options, and what effects different decisions may have.

Similarly, problem solving enables us to deal constructively with problems in our lives. Significant problems that are left unresolved can cause mental stress and give rise to accompanying physical strain.

Creative thinking contributes to both decision making and problem solving by enabling us to explore the available alternatives and various consequences of our actions or non-action. It helps us to look beyond our direct experience, and even if no problem is identified, or no decision is to be made, creative thinking can help us to respond adaptively and with flexibility to the situations of our daily lives. Critical thinking is an ability to analyze information and experiences in an objective manner. Critical thinking can contribute to health by helping us to recognize and assess the factors that influence attitudes and behavior, such as values, peer pressure, and the media.

Effective communication means that we are able to express ourselves, both verbally and nonverbally, in ways that are appropriate to our cultures and situations. This means being able to express opinions and desires, but also needs and fears. And it may mean being able to ask for advice and help in a time of need.

Interpersonal relationship skills help us to relate in positive ways with the people we interact with. This may mean being able to make and keep friendly relationships, which can be of great importance to our mental and social well-being. It may mean keeping good relations with family 


\section{The Role of Life Skills Training In Developing Emotional Maturity and Stress Resilience among Adolescents}

members, which are an important source of social support. It may also mean being able to end relationships constructively.

Self-awareness includes our recognition of ourselves, of our character, of our strengths and weaknesses, desires and dislikes. Developing self-awareness can help us to recognize when we are stressed or feel under pressure. It is also often a prerequisite for effective communication and interpersonal relations, as well as for developing empathy for others.

Empathy is the ability to imagine what life is like for another person, even in a situation that we may not be familiar with. Empathy can help us to understand and accept others who may be very different from ourselves, which can improve social interactions, for example, in situations of ethnic or cultural diversity. Empathy can also help to encourage nurturing behavior towards people in need of care and assistance, or tolerance, as is the case with AIDS sufferers, or people with mental disorders, who may be stigmatized and ostracized by the very people they depend upon for support. (WHO/MNH/PSF/93.7A.Rev.2)

Coping with emotions involves recognizing emotions in ourselves and others, being aware of how emotions influence behavior, and being able to respond to emotions appropriately. Intense emotions, like anger or sorrow can have negative effects on our health if we do not react appropriately.

Coping with stress is about recognizing the sources of stress in our lives, recognizing how this affects us, and acting in ways that help to control our levels of stress. This may mean that we take action to reduce the sources of stress, for example, by making changes to our physical environment or lifestyle. Or it may mean learning how to relax, so that tension secreted by unavoidable stress does not give rise to health problems.

The life skills described above are dealt with here in so far as they can be taught to young people as abilities that they can acquire through learning and practice. For example, problem solving, as a skill, can be described as a series of steps to go through, such as: 1)define the problem; 2) think of all the different kinds of solutions to the problem; 3) weigh up the advantages and disadvantages of each; 4) chose the most appropriate solution and plan how to realize it.

- Teaching life skills as generic skills in relation to everyday life could form the foundation of life skills education for the promotion of mental well-being, and healthy interaction and behavior. More problem specific skills, such as assertively dealing with peer pressures to use drugs, to have unprotected sex, or to become involved in vandalism, could be built on this foundation. There are research indications that teaching skills in this way, as part of broad-based life skills programmes, is an effective approach for primary prevention education (Errecart et al., 1991; Perry and Kelder, 1992; Caplan et al., 1992). 
- The model below shows the place of life skills as a link between motivating factors of knowledge, attitudes and values, and positive health behavior; and in this way contributing to the primary prevention of health problems.

\section{Knowledge, attitudes, values + Life skills for psychosocial competence + Behavioral reinforcement of change--------->positive health behavior-------> prevention of health problems.}

- Effective acquisition and application of life skills can influence the way we feel about ourselves and others, and equally will influence the way we are perceived by others. Life skills contribute to our perceptions of self-efficacy, self-confidence and self-esteem. Life skills therefore play an important role in the promotion of mental well-being. The promotion of mental well-being contributes to our motivation to look after ourselves and others, the prevention of mental disorders, and the prevention of health and behavior problems .Promoting the teaching of life skills

In promoting the teaching of life skills, the WHO is promoting the teaching of abilities that are often taken for granted. However, there is growing recognition that with changes in many cultures and lifestyles, many young people are not sufficiently equipped with life skills to help them deal with the increased demands and stresses they experience. They seem to lack the support required to acquire and reinforce life skills. It may be that traditional mechanisms for passing on life skills (e.g. family and cultural factors) are no longer adequate considering the influences that shape young people's development. These include media influence and the effects of growing up in situations of cultural and ethnic diversity. Also the rapid rate of social change, witnessed in many countries, makes the lives of young people, their expectations, values, and opportunities very different from that of their parents. Life skills for psychosocial competence need to be distinguished from other important skills that we hope young people will acquire as they grow up, such as reading, numeracy, technical and practical "livelihood" skills. These and other skills are usually recognized as abilities that young people should learn, either in schools, at home or in their communities.

Life skills are being promoted so that they can gain recognition as essential skills that should be included in the education of young people. Life Skills Education For health promotion, life skills education is based on the teaching of generic life skills and includes the practice of skills in relation to major health and social problems. Life skills lessons should be combined with health information, and may also be combined with other approaches, such as programmes designed to effect changes in environmental and social factors which influence the health and development of young people.

The methods used in the teaching of life skills builds upon what is known of how young people learn from their own experiences and from the people around them, from observing how others behave and what consequences arise from behavior. This is described in the Social Learning 
Theory developed by Bandura (1977). In Social Learning Theory learning is considered to be an active acquisition, processing and structuring of experiences.

In life skills education, children are actively involved in a dynamic teaching and learning process. The methods used to facilitate this active involvement include working in small groups and pairs, brainstorming, role play, games and debates. A life skills lesson may start with a teacher exploring with the students what their ideas or knowledge is about particular situation in which a life skill can be used. The children may be asked to discuss the issues raised in more detail in small groups or with a partner. They may then engage in short role play scenarios, or take part in activities that allow them to practice the skills in different situations - actual practice of skills is a vital component of life skills education.

Given the wide ranging relevance of life skills, an optimal strategy for the introduction of life skills teaching would be to make it available to all children and adolescents in schools .Life skills teaching promotes the learning of abilities that contribute to positive health behavior, positive interpersonal relationships, and mental well-being. Ideally, this learning should occur at a young age, before negative patterns of behavior and interaction have become established.

The school is an appropriate place for the introduction of life skills education because of:

- The role of schools in the socialization of young people;

- Access to children and adolescents on a large scale

- Economic efficiencies (uses existing infrastructure);

- experienced teachers already in place;

- High credibility with parents and community members;

- Possibilities for short and long term evaluation.

Even in countries where a significant proportion of children do not complete schooling, the introduction of life skills education in schools should be a priority. Life skills education is highly relevant to the daily needs of young people. When it is part of the school curriculum, the indications are that it helps to prevent school drop-out. Furthermore, once experience has been gained in the development and implementation of a life skills program for schools, this may help with the creation and implementation of programs for other settings.

\section{FOCUS ON PRESENT STUDY}

- The present study being an attempt to understand the concept of Life skills education and the influence of Life skills education on Emotional Maturity and Stress Resilience an attempt was made to review the relevant literature.

- The sources of studies for review literature are referred journals, books, dissertations, abstracts and the internet. 


\section{STUDIES ON LIFE SKILLS EDUCATION ITS IMPACT ON SOCIAL COMPETENCE} AND STRESS RESILIENCE

- Emotional Maturity is a complex, multidimensional concept consisting of social, emotional (e.g., affect regulation), cognitive (e.g., fund of information, skills for processing/acquisition, perspective taking), and behavioral (e.g., conversation skills, prosoical behavior) skills, as well as motivational and expectancy sets (e.g., moral development, self-efficacy) needed for successful social adaptation. Emotional competence also reflects having an ability to take another's perspective concerning a situation, learn from past experiences, and apply that learning to the changes in social interactions. Emotional Maturity is the foundation upon which expectations for future interaction with others are built, and upon which individuals develop perceptions of their own behavior. Often, the concept of Emotional Maturity frequently encompasses additional constructs such as social skills, social communication, and interpersonal communication.

- Resilience is the capacity to withstand stress and catastrophe. Psychologists have long recognized the capabilities of humans to adapt and overcome risk and adversity. Individuals and communities are able to rebuild their lives even after devastating tragedies.

The road to resilience lies in working through the emotions and effects of stress and painful-events.

Resilience is also not something that you're either born with or not. Resilience develops as people grow up and gain better thinking and self-management skills and more knowledge. Resilience also comes from supportive relationships with parents, peers and others, as well as cultural beliefs and traditions that help people cope with the inevitable bumps in life. Resilience is found in a variety of behaviors, thoughts, and actions that can be learned and developed across the life span.

\section{REVIEW OF LITERATURE}

- A Research study conducted by Esmaeil Sadri Damirchi of Hacettepe University, Turkey on The Impact of Life Skills Training Program on Emotional maturity AmongHigh School Students, 2013 emphasizes that the prepared Life Skills training program had been effective in increasing the Emotional maturity of High-school students in the experimental group. $(\mathrm{P} \leq 0 / 0001, \mathrm{t}=9 / 10)$. Based on this result, enhancing social development with a view of promoting social-emotional skills across different educational levels can be a practical objective. 
- A Research study conducted by Shanti Balda; UshaTuran(2012) Asian Journal of Home Science 2012 Vol. 7 No. 2 pp. 328-335.Life skills education for social competence and Emotional maturity of primary school children.The objective of the study was to determine the effectiveness of life skills training on social and emotional maturity of students with mathematics learning disorder. Life skills training improved social and emotional competence among the students with mathematics learning disorder and can be used as an appropriate approach for the improvement of children's social and emotional competence in learning disorder schools.

- A study conducted by Aparna UGC Research Scholar, Department of Education, University of Kerala, Thiruvananthapuram, Kerala, India and Raakhee Assistant professor, Department of psychology, S.N.College, Chempazhanthy, Thiruvananthapuram, Kerala, India. Education Science and Psychology 2011 | No.2 (19) ISSN 1512-1801 3. Life skills Education as stress resilience for Adolescents: its Relevance and Importance. Adolescents are considered to be the productive members of a society due to their physical and intellectual capacity. But unfortunately most of the adolescents are unable to utilize their potential to maximum due to inappropriate environment. They are always engaging in antisocial activities and spoiling their life. To make life of adolescents valuable and to convert them to individuals with high potential, educational system should be reformed giving due importance to life skill education. Life skills are those abilities which will help in the promotion of general well-being and psychosocial competence of the individual. Life skills empower young people to take positive action to protect them and promote health and positive social relationships. It also entails being able to establish productive interpersonal relationships with others. In the present paper the investigator goes through the importance of life skills, various life skills, life skill education and the benefits imparting life skill education in our curriculum.

- Aresearch study conducted by Reza Fallahchai, Hormozgan University, Bandar Abbas, Iran (2014) Effectiveness of Life Skills Instruction for stress resilience. The experimental group attended in 10 weekly sessions (35 hours) of life skills training. The results showed that the students who had received academic and life skills training gained significantly higher scores in life skills and stress resilience than those with no training.

\section{NEED FOR THE PRESENT STUDY}

An understanding of Emotional Maturity in adolescents, including its developmental antecedents and correlates as well as its relation to adaptive outcomes, is important for both theoretical and practical reasons. The development of adolescent Emotional Maturity and Resilience is central to theories of development and research on competence. From a practical standpoint, the promotion of Emotional Maturity and Resilience has been identified as a key resource for preventing 
adolescent problem behavior and enhancing positive development in children and adolescents. With this respect, the present paper focuses on "The Role of Life Skills Training in Developing Emotional maturity and Stress Resilience among adolescents”.

\section{METHOD:}

\section{Objective:}

- To study the Effect of Life Skills Training on Emotional Maturity and Stress Resilience.

\section{Hypothesis:}

- There is a significant difference between Life skill trained and untrained adolescents in their emotional maturity and stress resilience.

\section{Design:}

- The research method used in this study was quasi-experimental design with pre-test and post-test with control group and random assignment.

\section{Sample:}

- Purposive sampling technique was used to draw the sample, 20 trained female and 20 untrained female, studying in class 12 were selected from Bangalore city.

\section{Materials:}

The following materials were used in the present study:

- The Resilience Scale (RS), comprises of 25 items which has been designed by Gail M. Wagnild\& Heather M. Young.

- Emotional maturity Scale consists of 48 items which has been developed by Dr.Yashvir Singh and Dr. Mahesh Bhargava.

\section{ANALYSIS OF RESULTS:}

- Appropriate descriptive and inferential statistical analysis was used.

Table.1 shows the Mean and Standard deviation scores of emotional maturity of Experimental and Control group.

\begin{tabular}{|l|l|l|l|l|}
\hline Groups & Pre-test Mean & SD & Post-test Mean & SD \\
\hline Control Group & 0.98 & 0.18 & 5.53 & 0.18 \\
\hline $\begin{array}{l}\text { Experimental } \\
\text { Group }\end{array}$ & 1.33 & 0.16 & 1.65 & 0.625 \\
\hline
\end{tabular}


Table.2 shows the Mean and Standard deviation scores of Stress Resilience of Experimental and Control group.

\begin{tabular}{|l|l|l|l|l|}
\hline Groups & Pre-test Mean & SD & Post-test Mean & SD \\
\hline Control Group & 1.3 & 0.77 & 1.114 & 1 \\
\hline $\begin{array}{l}\text { Experimental } \\
\text { Group }\end{array}$ & 3.7 & 0.29 & 0.29 & 1.6 \\
\hline
\end{tabular}

Table.3 shows the multivariate analysis of covariance for the effects of life skills training on increase in emotional maturity.

\begin{tabular}{|l|l|l|l|l|l|l|l|}
\hline $\begin{array}{l}\text { Partial } \\
\text { Eta } \\
\text { Squared }\end{array}$ & Sig & F value & $\begin{array}{l}\text { Mean } \\
\text { Square }\end{array}$ & Df & $\begin{array}{l}\text { Sum of } \\
\text { squares }\end{array}$ & $\begin{array}{l}\text { emotional } \\
\text { maturity } \\
\text { components }\end{array}$ & $\begin{array}{l}\text { Effect } \\
\text { sources }\end{array}$ \\
\hline $0 / 45$ & $0 / 00$ & 0.40 & 3.147 & 1.35 & $299 / 95$ & $\begin{array}{l}\text { Evaluation and } \\
\text { expression } \\
\text { emotions }\end{array}$ & $\begin{array}{l}\text { Life } \\
\text { Skills } \\
\text { Training }\end{array}$ \\
\hline $0 / 26$ & $0 / 001$ & 0.22 & 2.64 & 1.35 & $185 / 70$ & $\begin{array}{l}\text { Emotion } \\
\text { regulation }\end{array}$ & \\
\hline $0 / 32$ & $0 / 000$ & 2.83 & 5.33 & 1.35 & $315 / 59$ & Emotionutilization & \\
\hline
\end{tabular}

Table. 4 shows the covariance analysis to examine the effects of life skills training on increase in Stress Resilience.

\begin{tabular}{|l|l|l|l|l|l|l|}
\hline $\begin{array}{l}\text { Partial Eta } \\
\text { Squared }\end{array}$ & Sig & F value & $\begin{array}{l}\text { Mean } \\
\text { Square }\end{array}$ & df & $\begin{array}{l}\text { Sum of } \\
\text { squares }\end{array}$ & Effects \\
\hline $0 / 11$ & $0 / 03$ & 0.0625 & 1.145 & 1 & 1.145 & $\begin{array}{l}\text { Effect } \\
\text { group(Life } \\
\text { Skills } \\
\text { Training) }\end{array}$ \\
\hline & & & & & & \\
\hline & & & 0.35 & 37 & 8.90625 & Error \\
\hline & & & & 40 & 65460 & Total \\
\hline
\end{tabular}

According to table.1 and table.2, we can infer that the mean scores of the Experimental group in the pre-test for emotional maturity was 1.33, which has increased to 1.65 in the post-test and the mean scores for stress resilience of the experimental group in pre-test was 3.7 which has increased to 0.29 in the post test. 
According to table.3, we can infer that the mean difference between the components of emotional regulation, evaluation and express emotion, and emotion utilization, in post test of experimental group is statistically significant that training life skills can result in increase in emotional maturity.

Generally with the values of square Eta in Table.3, it can be pointed out that life skills training have the greatest impact on the evaluation and express emotion (45 percent), and then it has greatest impact on emotion utilization (32 percent) and emotional regulation (26 percent).

According to table.4, we can infer that the difference in the stress resilience scores between the experimental and control group is statistically significant, in a way that training life skills can result in increase in stress resilience .According to the Eta squared, value of this effect is $11 \%($ table.4).

\section{DISCUSSION}

The aim of the research study was to analyze the effect/role of Life Skills Training on Emotional Maturity and Stress Resilience among trained and untrained adolescents studying in class 12. The result of the study depicts that Life Skills Training increases Emotional Maturity and Stress Resilience among the students who had participated in the Life Skills Training class.

\section{CONCLUSION}

Although the generalizability of these results requires further research in this field, it can be stated that training life skills can greatly increase emotional maturity and stress resilience among adolescents. Life Skills Training should be interest of professionals and authorities in the field.

The purpose of training life skills is to foster the ability in individuals to deal with problems and Stressful life, so that they can achieve and promote their mental health.

\section{REFERENCES}

Esmaeil Sadri Damirchi of Hacettepe University, Turkey on The Impact of Life Skills Training Program on Emotional maturity Among High School Students,: journal of emerging trends in educational research and policy studies (jeteraps) 3(4):395-401.

Shanti Balda; UshaTuran (2012) Life skills education for social competence and Emotional maturity of primary school children: Asian Journal of Home Science 2012 Vol. 7 No. 2 pp. 328-335.

Aparna and Raakhee (2011) Life skills Education as stress resilience for Adolescents: its Relevance and Importance: Education Science and Psychology | No.2 (19) ISSN 151218013 
Reza Fallahchai, Hormozgan University, Bandar Abbas, Iran (2014) Effectiveness of Life Skills Instruction for stress resilience. American educational research journal, 38, 437-460.

"Life Skills." UNICEF. www.unicef.org/lifeskills.

"Life Skills.” Wikipedia. http://en.wikipedia.org/wiki/Life_skills.

"Life Skills.” World Health Organization. 1993. www.who.org.

World Health Organization. (1999). Partners in life-skills education. Geneva, Switzerland: World Health Organization, Department of Mental Health.

World Health Organization (1994). The development and dissemination of life skills education: An overview. Geneva: Division of Mental Health, World Health Organization. 